\title{
Publisher Correction: Small GTPases and BAR domain proteins regulate branched actin polymerisation for clathrin and dynamin- independent endocytosis
}

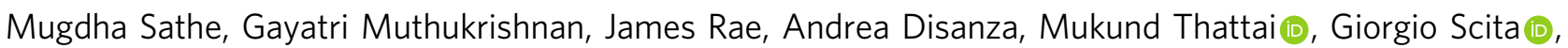
Robert G. Parton (1) \& Satyajit Mayor

Correction to: Nature Communications https://doi.org/10.1038/s41467-018-03955-w; published online 9 May 2018.

The original version of this Article contains an error in Fig. 1e, in which the representative image panel was inadvertently duplicated from Fig. 1d by the publisher.

The correct representative image version of Fig. 1e is:

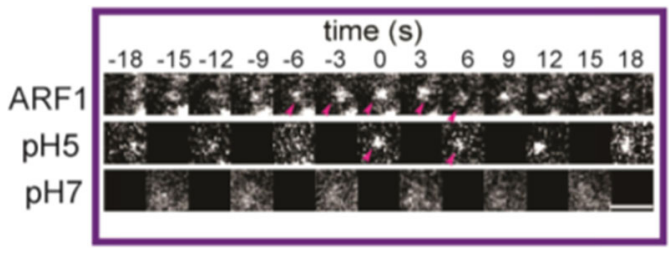

The incorrect version is:

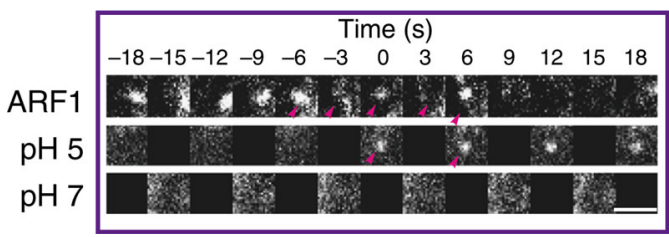

In addition, in Fig. 5b, the dataset used is the same as for Fig. $1 \mathrm{~d}$ along with its representative image. Both panels $1 \mathrm{~d}$ and $5 \mathrm{~b}$ present quantifications of the same CDC42 dataset but from different zones as indicated, to compare with the analysis of IRSp53 dataset in 5a.

Clarifications have been added to the legend of Fig. $5 \mathrm{~b}$ below to reflect that the same dataset was used in the two quantifications and the legend should read:

"b Graphs show the average normalised fluorescence intensity vs. time traces for the recruitment of TagRFPt-CDC42 (dataset taken from Fig. 1d, quantifications done using different zones) to the forming SecGFP-GPI endocytic sites and its corresponding random intensity trace to two different regions [circle, black, $r=250 \mathrm{~nm}$; and annulus, orange $(r=250-420 \mathrm{~nm})$ ]. Error bars, $(\mathbf{a}-\mathbf{b})$ represent s.e.m. ( $n$, Table 1). The random traces were derived from randomly assigned spots of the same radius as the endocytic regions, as 
detailed in S.I. Endocytic distribution at each time point was compared to the random distribution by Mann-Whitney $U$ test and the $\log _{10}(p)$ is plotted below each trace here (a) or in Fig. $1 \mathrm{~d}(\mathbf{b})\left[\log _{10}(0.05)\right.$ is -1.3 and $\log _{10}(0.001)$ is -2.5$]$. Representative montages $(\mathbf{a}-\mathbf{b})$ are depicted below the graphs (Note: $5 \mathrm{~b}$ is reproduced from $1 \mathrm{~d}) . "$

This original text is:

"b Graphs show the average normalised fluorescence intensity vs. time traces for the recruitment of TagRFPt-CDC42 to the forming SecGFP-GPI endocytic sites and its corresponding random intensity trace to two different regions [circle, black, $r=250 \mathrm{~nm}$; and annulus, orange $(r=250-420 \mathrm{~nm})$ ]. Error bars, $(\mathbf{a}-\mathbf{b})$ represent s.e.m. ( $n$, Table 1$)$. The random traces were derived from randomly assigned spots of the same radius as the endocytic regions, as detailed in S.I. Endocytic distribution at each time point was compared to the random distribution by Mann-Whitney $U$ test and the $\log _{10}(p)$ is plotted below each trace $\left[\log _{10}(0.05)\right.$ is -1.3 and $\log _{10}(0.001)$ is $-2.5]$. Representative montages are depicted below the graphs."

Published online: 23 August 2021

\begin{abstract}
(c) (i) Open Access This article is licensed under a Creative Commons Attribution 4.0 International License, which permits use, sharing, adaptation, distribution and reproduction in any medium or format, as long as you give appropriate credit to the original author(s) and the source, provide a link to the Creative Commons license, and indicate if changes were made. The images or other third party material in this article are included in the article's Creative Commons license, unless indicated otherwise in a credit line to the material. If material is not included in the article's Creative Commons license and your intended use is not permitted by statutory regulation or exceeds the permitted use, you will need to obtain permission directly from the copyright holder. To view a copy of this license, visit http://creativecommons.org/licenses/by/4.0/.
\end{abstract}

(c) The Author(s) 2021 